\title{
Participation opportunities for persons with disabilities in training interventions in the dti and CIPRO
}

\begin{tabular}{|c|c|}
\hline \multicolumn{2}{|c|}{$\begin{array}{l}\text { Authors: } \\
\text { Zelna van Niekerk }{ }^{1} \\
\text { John van der Merwe }\end{array}$} \\
\hline \multicolumn{2}{|c|}{$\begin{array}{l}\text { Affiliations: } \\
{ }^{1} \text { Department of Human } \\
\text { Resource Management, } \\
\text { University of South Africa, } \\
\text { South Africa }\end{array}$} \\
\hline \multicolumn{2}{|c|}{$\begin{array}{l}{ }^{2} \text { Department of Training and } \\
\text { Development, North-West } \\
\text { University, South Africa }\end{array}$} \\
\hline \multicolumn{2}{|c|}{$\begin{array}{l}\text { Correspondence to: } \\
\text { Zelna van Niekerk }\end{array}$} \\
\hline \multicolumn{2}{|c|}{$\begin{array}{l}\text { Email: } \\
\text { vniekz@unisa.ac.za }\end{array}$} \\
\hline \multicolumn{2}{|c|}{$\begin{array}{l}\text { Postal address: } \\
\text { PO Box 392, Unisa 0003, } \\
\text { South Africa }\end{array}$} \\
\hline \multicolumn{2}{|c|}{$\begin{array}{l}\text { Dates: } \\
\text { Received: } 06 \text { Mar. } 2012 \\
\text { Accepted: } 21 \text { Jan. } 2013 \\
\text { Published: } 29 \text { Apr. } 2013\end{array}$} \\
\hline \multicolumn{2}{|c|}{$\begin{array}{l}\text { How to cite this article: } \\
\text { Van Niekerk, Z., \& Van } \\
\text { der Merwe, J. (2013). } \\
\text { Participation opportunities } \\
\text { for persons with disabilities } \\
\text { in training interventions } \\
\text { in the dti and CIPRO. SA } \\
\text { Journal of Human Resource } \\
\text { Management/SA Tydskrif vir } \\
\text { Menslikehulpbronbestuur, } \\
\text { 11(1), Art. \#466, } 12 \text { pages. } \\
\text { http://dx.doi.org/10.4102/ } \\
\text { sajhrm.v11i1.466 }\end{array}$} \\
\hline \multicolumn{2}{|c|}{$\begin{array}{l}\text { Copyright: } \\
\text { (C) 2013. The Authors. } \\
\text { Licensee: AOSIS } \\
\text { OpenJournals. This work } \\
\text { is licensed under the } \\
\text { Creative Commons } \\
\text { Attribution License. }\end{array}$} \\
\hline \multicolumn{2}{|c|}{ Read online: } \\
\hline 口ifra & $\begin{array}{l}\text { Scan this QR } \\
\text { code with your } \\
\text { smart phone or } \\
\text { mobile device } \\
\text { to read online. }\end{array}$ \\
\hline
\end{tabular}

Orientation: Persons with disabilities (PWD) face daily barriers which often hinder them in fully participating in society or reaching their full potential. They often have little or no exposure to formal education and only are employed at entry-level positions. When employed, they are often not trained or developed.

Research purpose: The purpose of this study was to determine the extent to which PWD in a public service department were exposed to training and development opportunities valuable for career advancement.

Motivation for the study: The primary researcher is living with a disability and has not only experienced discrimination but has also witnessed it throughout her career in the Public Service.

Research design, approach and method: The researchers followed a qualitative research design using semi-structured interviews and document analysis. A non-probability, purposive sampling technique was used given the limited number of PWD employed and seven interviews were conducted in the organisations.

Main findings: The perceptions of the participants were that they were mainly exposed to repetitive, low-level training leading to little or no career advancement. A document analysis of the number of PWD trained and employees without disabilities trained, showed an unequal distribution.

Practical/managerial implications: The organisations need to address the unfairness through their policies, ensuring increased and equally valuable training and development opportunities for PWD.

Contribution/value-add: The findings of this study provide an understanding of the exposure of PWD to valuable training and development opportunities and show that inequality still exists and needs to be addressed.

\section{Introduction}

\section{Problem statement}

\section{Key focus}

I exhort all of you here today to see yourselves as pioneers who wear the cloak of audacity, not only to transform the Public Service, but to turn it into a powerful agent for development so that the people are able to access what is rightfully theirs and which for too long they were unjustly denied. (Fraser-Moleketi, 2008, p. 1)

The main objectives of the above statement, issued by Ms Geraldine Fraser-Moleketi in her capacity as Minister of the Department Public Service and Administration (DPSA), were to introduce a new era for persons with disability (PWD) in the South African context and to create opportunities for the Public Service to treat PWD as equal to those without disabilities. Today, more than five years later, the question remains whether there have been any positive changes in this regard.

\section{Background to the study}

The workplace should take every action to address the historical inequalities suffered by PWD as intended by The Bill of Rights (Republic of South Africa [RSA], 1996), which stresses equal treatment for all. Equality should help PWD to become socially and economically independent and to reach self-actualisation (Ngwena, 2004). According to the JobACCESS strategic framework (Department of Public Service and Administration [DPSA], 2008a), PWD are one of the most disadvantaged groups in society, with less likelihood to obtain educational qualifications or to be employed. It also indicates that PWD face communication and transport barriers and are likely to have lower or no income and fewer financial resources than people without disabilities (PWoD) (DPSA, 2008a). In addition to this, public attitudes to disability have a negative impact on PWD. 
This widespread ignorance, fear and stereotyping have caused unfair discrimination against PWD in society and a lack of employment, training and development opportunities for them (DPSA, 2008a).

The World report on disability reiterates this for developing countries (World Health Organization [WHO], 2011), where PWD are not given equal opportunities in the educational sector or labour market. The United Nations convention on the rights of PWD (United Nations [UN], 2008) states that these members of society all around the world are still denied equal participation which is a direct violation of their human rights. Although this research project and article focused on the South African context, it is clear from the above that equal opportunities for PWD are still lacking all over the world.

\section{Research purpose}

The purpose of this research study was to determine the extent to which PWD at the Department of Trade and Industry (dti) and the Companies and Intellectual Property Registration Office (CIPRO) were exposed to training and development opportunities and whether these interventions in any way prepared them for career advancement. It is important to assess whether the previous disadvantaged position of PWD is being addressed. The Employment Equity Act (EE Act) (Act No. 55 of 1998) (RSA, 1998a) is intended to redress the disadvantages in employment experienced by designated groups, including PWD.

The target for the employment of PWD in the Public Service was $2.00 \%$, originally set by Cabinet in the White paper on the transformation of the Public Service (RSA, 1995). According to research conducted in 2008 by the DPSA (2008b), PWD constituted only $0.16 \%$ of the total number of employees in the Public Service by December 2005. According to the 2010 annual report of the Commission for Employment Equity (CEE) (2012), the representation of PWD in the Public Service was $0.60 \%$ and in 2012 it was $0.80 \%$ for the whole labour force. This clearly shows that there has been very little progress towards meeting the $2.00 \%$ employment target.

Furthermore, the researchers also considered whether the training offered to PWD in the dti and CIPRO contributed to career advancement. Vila, Pallisera and Fullana (2007) stressed the importance of skills and qualifications to integrate PWD into the workplace and improve their career advancement opportunities.

\section{Trends from the research literature}

The Handbook on reasonable accommodation for PWD in the Public Service (DPSA, 2007) specifies that departments should implement measures to ensure equitable representation of suitably qualified people from designated groups in all occupational categories, their retention and development as well as the implementation of appropriate training measures, in terms of the Skills Development Act (Act No. 97 of 1998) (RSA, 1998b).
The Services Sector Education and Training Authority (SETA) (2006), in their training toolkit on the employment of PWD, mentioned that the development of PWD through learnerships or workplace mentoring and coaching, as well as accelerated training programmes that can make them eligible for promotion, should be seen as part of any organisation's affirmative action interventions.

\section{Research objectives of this study}

The general aim of the research was to determine to what extent the dti and CIPRO, as members of the Public Service, have been successful in offering equal and valuable training and development opportunities to PWD in their departments. At the time of the study in 2010, CIPRO was still an agency of the dti, but since 2011 it has been known as CIPC, the Companies and Intellectual Property Commission, reporting to its own commissioner rather than the minister of the DPSA. Although both the dti and CIPRO have successfully employed PWD, this article sheds more light on whether these PWD were equally exposed to training interventions, compared to their counterparts without disabilities, and therefore whether they were equally advanced in terms of skills development, as mentioned in the JobACCESS strategic framework (DPSA, 2008a).

The objectives of the research were to:

- Explore to what extend PWD employed by the dti and CIPRO perceive that they are equally advanced in terms of skills development when compared with PWoD.

- Through document analysis, verify to what extent PWD were exposed to training interventions in the dti and CIPRO in comparison to PWoD.

- Make recommendations to the management of the dti and CIPRO regarding the empowerment of PWD in terms of training and development opportunities when compared with PWoD.

\section{Contribution to field}

During this study, the lack of research regarding education, training and development (ETD) of PWD was apparent. This study intended to add some insight into whether PWD are as equally exposed to training interventions as their nondisabled counterparts and therefore are as equally advanced in terms of skills development addressing their previously disadvantaged position. The researchers also hoped to create a greater interest in this research topic. Future studies at other government departments and/or the private sector could provide an even better understanding of the extent to which PWD are exposed to training and development interventions.

\section{What will follow}

The article will subsequently look at the research approach, data collection and analysis techniques the researchers used during this study, followed by an examination of the data collected during the interviews with the voluntary participants in the dti and CIPRO and the findings made based on these data. These data and the analysis thereof lead 
to certain conclusions that were made and which will also be discussed later in the article.

\section{Literature review}

\section{Understanding disability}

The United Nations convention on the rights of PWD defines PWD as:

... those who have long term physical, mental, intellectual or sensory impairments which, in interaction with various barriers, may hinder their full and effective participation in society on equal basis with others. (UN, 2008, p. 4)

In South Africa, the EE Act (RSA, 1998a, p. 7) defines PWD as 'people who have a long-term or recurring physical or mental impairment which substantially limits their prospects of entry into, or advancement in, employment'. 'Long-term' denotes a recurrent impairment that lasts for more than 12 months and includes progressive conditions that develop, change or recur over a period of time (e.g. degenerative conditions such as multiple sclerosis).

Different types of impairments are classified in the Act as disabilities, for example, 'a physical impairment refers to a partial or total loss of a bodily function or part of the body' (RSA, 1998a, p. 7) and it includes in its definition sensory impairments such as hearing or visual disabilities (RSA, 1998a). The second type is mental impairments, which are clinically recognised conditions affecting a person's thought processes, judgement or emotions. The Act's definition indicates that these impairments must be substantially limiting in terms of a person's ability to perform the essential functions of the job for which considered or employed (RSA, 1998a). Therefore, PWD will not be able to perform all the usual core job functions and might need the workplace or the job function to be adapted to ensure full participation in the workplace. This is usually achieved through reasonable accommodation measures and disability management (Department of Labour [DoL], 2003).

However, in their Report on disability equity in the Public Service, the Public Service Commission (2008) found that defining disabilities in terms of 'physical or mental impairments' confused both employers and employees and failed to indicate when an impairment could be considered as substantially limiting. The definition included in the JobACCESS strategy (DPSA, 2006) provides a more encompassing definition in an effort to provide a clearer understanding of 'disability'. The definition states:

The loss or elimination of opportunities to take part in the life of the community equitably with others that is encountered by people having physical, sensory, psychological, developmental, learning, neurological, or other impairments, which may be permanent, temporary or episodic in nature, thereby causing activity limitations and participation restriction with the mainstream society. These barriers may be due to economic, physical, social, attitudinal and/or cultural factors. (DPSA, 2006, p. 44)

In addition to understanding the definition of disability, it is also important to understand the different types of disabilities. Figure 1 provides an overview of the different

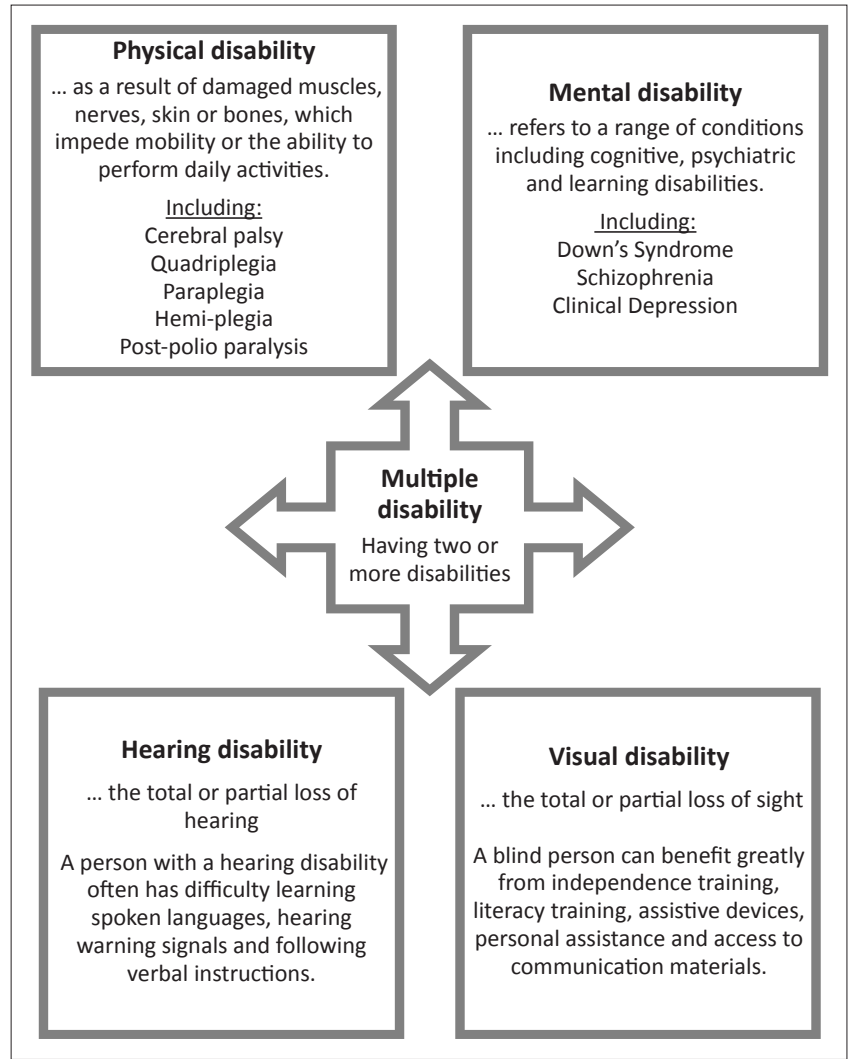

Source: Services Sector Education and Training Authority Toolkit (2006). Employing and managing PWD. Parktown: Services SETA.

FIGURE 1: Categories of disabilities.

categories of disabilities, which include physical, mental and sensory disabilities. The disabilities mentioned in Figure 1 are however not exclusive.

\section{The status of disability}

In order to determine the equal treatment of PWD in terms of training and development (perceived and substantiated), which forms part of the objectives of this study, it is important to consider the status of disability in South Africa. The EE Act (RSA, 1998a) mainly prohibits unfair discrimination in employment whilst introducing affirmative action. The Act places specific emphasis on ensuring equity, the right to equal protection and benefit of the law, inter alia, for PWD (RSA, 1998a).

Kleynhans and Kotzé (2010) indicate that the general negative attitude of managers towards PWD limits their opportunities for employment, career advancement and/or training. According to Ngwena (2004), the treatment of PWD in the workplace raises difficult questions about how to secure full enjoyment of human dignity, equality and freedom for such a marginalised minority and it is suggested that all steps must be taken to curb this marginalisation. In the 2001 National Census (Statistics South Africa [StatsSA], 2003), it was estimated that there were 2.25 million South Africans living with disabilities. This figure represented $5.03 \%$ of the total South African population, decreasing from 5.03\% to $4.00 \%$ in 2007 (StatsSA, 2007). To consider the more recent 2011 Census statistics, the following should be noted: 'Questions on disability were replaced by general health 
and functioning questions. Due to change in question, 2011 results are not comparable with previous Censuses 1996 and 2001' (StatsSA, 2012, p. ii). This is because the questions used in the 2011 Census referred to persons with difficulty instead of disability, as per suggestions by the Washington Group (WG). The 2011 Census report mentions that:

Many countries that adopted the WG questions believe that this approach of measuring disability provides adequate estimates compared to the traditional approach where only severe disabilities are measured, leading to underestimation of PWD. (StatsSA, 2012, p. 39)

Therefore the latest Census results only indicate that more than $90 \%$ of South Africans experienced no difficulty in conducting their daily functions.

In the 2010 annual report of the CEE (2010a), the acting chairperson, Ms Mpho Nkeli, indicated that with reference to all designated groups, very little progress had been made in the labour force which could lead to young, qualified people still not finding suitable employment. This emphasises the slow transformation in this particular area and reinforces the fact that South Africa still has a long way to go in terms of affirmative action involving all designated groups, including PWD.

\section{Disability and training}

According to the Disability in the workplace: Company practices report compiled by the International Labour Organization (ILO):

PWD represent an untapped source of skills and talent, including technical skills if they have access to training, and transferable problem-solving skills developed in daily life. People who develop disabilities while working often have valuable skills and experiences learned on the job, in addition to their formal skills qualifications. (ILO, 2010, p. 1)

This stresses the importance of developing PWD which can be very valuable in organisations.

For this research project, it was important to review available research about the relationship between PWD and the extent to which they were exposed to training and development opportunities, as well as the perceptions and relevant documented proof that exist. According to the Promotion of Equality and Prevention of Unfair Discrimination Act (Act No. 4 of 2000) (RSA, 2000):

\footnotetext{
... no person may unfairly discriminate, directly or indirectly, against an employee in any employment policy or practice, on one or more grounds including race, gender, sex, pregnancy, marital status, family responsibility, ethnic or social origin, sexual orientation, age, disability, religion, HIV status, conscience, belief, political opinion, culture, language or birth. (RSA, 2000, p.8)
}

Therefore, discriminating against PWD in terms of ETD is clearly in contravention of the abovementioned Act. The Services SETA toolkit (2006) views intentionally denying PWD equal access to training and career advancement as direct discrimination. Kleynhans and Kotze (2010) state that organisations and managers often avoid the training of PWD as they feel there will be disproportionally high costs associated with the training of these employees. However, they found that in reality this cost is often minimal and therefore managers should reconsider their negative attitudes.

The National skills development strategy III (NSDS III) (Department for Higher Education and Training [DHET], 2010) reports the following on the progress regarding the development of PWD:

Despite commitments from NSDS I and II to increase opportunities for training and skills development for PWD, we are still far from achieving our goals in this regard. Therefore, NSDS III aims to significantly open up opportunities for skills training for people experiencing barriers to employment caused by various forms of physical and intellectual disability. (DHET, 2010, p. 8)

Cassim (2005) stresses that although South Africa has considerable legislation, including the EE Act (RSA, 1998a) and the Skills Development Act (RSA, 1998b), in place to ensure that more PWD receive employment as well as training and development, progress in both the public and private sector in South Africa remains unsatisfactory. The perception that exists with regards to PWD being less skilled and qualified is also reflected in the CEE Annual report for 2010 (CEE, 2010b) when 24608 of the 38781 PWD in the South African labour market were at the semi-skilled and unskilled levels. In 2012 we found a positive trend in this regard, as not only did the numbers of PWD increase to 40 550, but 16130 PWD against the 14173 of 2010 were now skilled (CEE, 2012).

\section{Training and career advancement}

\section{The NSDS III stresses that:}

This strategy represents an explicit commitment to encouraging linking of skills development to career paths, career development and promoting sustainable employment and in-work progression. (DHET, 2010, p. 5)

PWD must be able to make inputs on their career advancement possibilities. According to the Technical assistance guidelines on the employment of PWD (DoL, 2003), decisions need to be made on where the PWD are and where they anticipate going with their career, as well how they will get there. This plan should also identify the training the employee will need in order to reach these career goals. As part of the implementation of this career plan, all effort must be made to ensure that the training facilities and material will be accessible and suitable for PWD.

According to Vila et al. (2007), the training institutions, as well as how these facilities influence the training of PWD, must be considered, as this influences the career and work life development of PWD. Engelbrecht (2010) states that employers who commit themselves to career advancement of PWD and develop strategies to this effect will become employers of choice for PWD. Just as PWoD want job satisfaction and the chance to have a career with opportunities to advance, PWD have the same needs (Lengnick-Hall, Gaunt \& Kulkarni, 2008).

\section{Persons with disabilities per educational level}

The World report on disability $(\mathrm{WHO}, 2011)$ reported statistics which were collected during a $2002-2004$ survey conducted 
TABLE 1: Education outcomes for disabled and not-disabled respondents in 2002-2004.

\begin{tabular}{|c|c|c|c|c|c|c|}
\hline \multirow[t]{2}{*}{ Individuals } & \multicolumn{2}{|c|}{ Low-income countries } & \multicolumn{2}{|c|}{ High-income countries } & \multicolumn{2}{|c|}{ All countries } \\
\hline & Not Disabled (\%) & Disabled (\%) & Not Disabled (\%) & Disabled (\%) & Not Disabled (\%) & Disabled (\%) \\
\hline Male - Primary school completion & 55.6 & 45.6 & 72.3 & 61.7 & 61.3 & 50.6 \\
\hline Female - Primary school completion & 42.0 & 32.9 & 72.0 & 59.3 & 52.9 & 41.7 \\
\hline
\end{tabular}

Source: Adapted from World Health Organization (2011). World report on disability. Geneva: WHO Library Cataloguing in Publication Data.

in 51 countries. In all categories, in both low-income and high-income countries, PWD completing primary school were around $10 \%$ lower than their non-disabled counterparts (as shown in Table 1).

The 2001 Census (StatsSA, 2003) found that 10.5\% of PWD had no education, $3.9 \%$ had completed secondary school and $3.0 \%$ of PWD graduated from tertiary institutions in 2001. According to Crous (2004), who conducted a survey amongst 751 students at three South African universities, only $0.5 \%$ of the students enrolled at these universities had impairments. It follows that increasingly more South Africans with disabilities are left to find employment with low levels of education.

When the primary researcher looked at the educational status of PWD in other countries, she found that in a study by Hergenrather, Rhodes, Turner and Barlouw (2008), in which the respondents were 577 Americans with disability, 32.9\% had a high school diploma. In 2006 in Canada, 24.5\% of PWD had a high school education (Statistics Canada, 2006).

Education directly influences the chances of employment, advancement and training of PWD. In the 10th annual CEE report (2010a), the commission indicated that although there was some representation of PWD at all occupational levels, the majority of these employees were still employed at the lower levels, with only $17.5 \%$ of all employed PWD being employed as middle and senior management.

\section{Research design}

In this study, the data collected had to be interpreted in a manner that would add to the understanding of the training and development opportunities received by the PWD in the dti and CIPRO. The researchers decided to follow a qualitative research approach. As stated by Leedy and Ormrod (2005), the purpose of qualitative research is to obtain a better understanding of a phenomenon or situation. Therefore, it was considered the most suitable approach to explore the experiences, perceptions and feelings of PWD in the dti and CIPRO regarding training and development opportunities offered to them.

\section{Research approach}

An interactive approach was followed to collect the qualitative data in this project through one-on-one semi-structured interviews with voluntary participants. The departmental workplace skills plans (WSPs) and annual training reports (ATRs) for 2009 and 2010 were also collected for analysis in an attempt to verify the data collected during the interviews.

\section{Research strategy}

As part of a qualitative research approach, the researchers used a case study method where a single case (the dti and its agency CIPRO) were used to study how PWD perceive their training and development opportunities and then, in an effort to support or negate the perceptions of the case study participants, document analyses of official departmental reports were conducted. As an output of the case study, the researchers then made recommendations to the relevant managers on the research findings. A case study, according to Leedy and Ormrod (2005), is an in-depth qualitative study of a single event or case to create a better understanding of it. Therefore the researchers found this to be a suitable methodology to understand the training and development opportunities of the PWD in this case better.

\section{Research method}

\section{Research setting}

Qualitative data were collected through seven individual semi-structured interviews with employees with declared disabilities in accordance with the EE Act (RSA, 1998a) in the organisations. All employees with declared disabilities were identified by the disability managers in the organisations and then had the choice to participate in the study. The interviews were conducted on the same day at the dti campus and lasted between 30 minutes and 45 minutes. Interviews were used in an attempt to gather first-hand data whilst ensuring confidentiality in a safe environment where interviewees could be honest and at ease. Participation was voluntary, participants were informed that they could withdraw from the project at any time and they completed the consent form accordingly.

The WSPs and ATRs compiled by the two offices, in line with requirements of the Public Service Sectoral Education and Training Authority (PSETA), were sourced as official annual training statistics in an effort to support or negate the data collected during the interviews.

\section{Entrée and establishing researcher roles}

Initially, the primary researcher applied for permission to conduct the research in five different Public Service national departments, but only received feedback and consequent permission from the director general of the dit to conduct the research. Next, the primary researcher contacted the disability managers at these two offices in order to make contact with the employees with declared disabilities through an introduction letter, after which written consent was obtained from those employees willing to participate. Finally, the reports used during the document analysis (WSPs and ATRs) were requested from PSETA. 


\section{Sampling}

Non-probability, purposive sampling was used in the study. Given the limited number of PWD formally employed, and the fact that the study focused only on the dti and CIPRO, as mentioned above, the primary researcher contacted the persons with declared disabilities, in terms of the EE Act definition (RSA, 1998a), in these organisations with the help of the relevant disability managers and an introduction letter. The final research sample consisted of seven participants with disabilities employed by either the national office of the dti (four employees) or CIPRO (three employees) (Table 2).

\section{Data collection methods}

Data were collected through individual, semi-structured interviews personally conducted by the primary researcher. This afforded the researcher the opportunity to interact directly with the participants, to put them at ease, build trust and prompt participants in order to collect as much information as possible. The statistics reflected in the relevant departmental WSPs, ATRs and employment equity statistics for both the dti and CIPRO were analysed to determine to what extent the proposed training for PWD has been achieved. The WSPs reflect the proposed training for a financial year, whilst the ATRs reflect the actual training conducted.

The following questions were included in the qualitative interview questionnaire:

1. To what extend do you believe does the dti or CIPRO support the development of PWD?

2. Have you attended any training courses in the past financial year?

3. Did you ask to attend this course or did your manager nominate you for the course?

4. Was the course you attended applicable to your work or do you feel that it made you a better employee for the dti or CIPRO?

5. How long have you been in the Public Service?

6. Have you been in the dti or CIPRO for the whole period or have you been in other Public Service departments also?

7. In your service record with the dti or CIPRO have you ever been promoted?

8. How do you feel about the dti's or CIPRO's approach to PWD in the general workplace?

9. Do you think the dti or CIPRO treat PWD differently or do you think they give these employees equal opportunities?

The questions focused whether the PWD attended work-related training (Questions 2 and 4), whether the training contributed to their career management (nomination) (Question 3) and career

TABLE 2 Demographical information of study participants.

\begin{tabular}{llllll}
\hline Participant & Race & Gender & Disability & $\begin{array}{l}\text { Job experience } \\
\text { (years) }\end{array}$ & Job level \\
\hline Participant 1 & White & Male & Physical & 25 & Clerical \\
Participant 2 & Black & Male & Sensory & 4 & Clerical \\
Participant 3 & Black & Male & Physical & 25 & Line manager \\
Participant 4 & Black & Male & Physical & 5 & Supervisor \\
Participant 5 & Black & Female & Physical & 14 & Clerical \\
Participant 6 & White & Female & Physical & 12 & Clerical \\
Participant 7 & Black & Female & Sensory & 3 & Clerical \\
\hline
\end{tabular}

advancement (Questions 5-7) and on determining whether the participants experienced equal developmental and workplace opportunities (Questions 1, 8 and 9).

The literature review included, but was not limited to, academic books and scientific journal articles, policy documents, legislation and additional departmental documents reflecting relevant statistical training data. The analysis of the relevant WSPs and ATRs provided information on the number of PWD that took part in training and development interventions in the dti and CIPRO.

\section{Recording of data}

All the interviews were audiotaped and transcribed verbatim for future referral and the primary researcher also observed the participants during the interviews and made field notes for referral purposes.

\section{Data analyses}

The researchers considered the various data analysis methods and decided that grounded theory and content analysis would be the most suitable for this study. Although content analysis also played a big role in the data collected during the individual interviews, the researcher focused more on the grounded theory approach. Ratcliff (2002) proposed the identification of indicators of categories in events and behaviour which are then named and coded. This helped the researchers to compare the codes in order to find consistencies and differences; the consistencies were used to identify different categories. These categories became saturated when no new codes related to the specific category could be found. In this research study, the researchers identified similarities and consequent categories and themes that became apparent during the individual interviews with the PWD. The researchers then studied these themes and categories to create a better understanding of issues related to training and development of PWD. This coding process helped the researchers to identify similar feelings and themes from the responses of the participants. These themes formed the basis for the findings that are discussed later.

As mentioned above, the researchers also used content analysis in this study. Stemler (2001, p. 1) defines content analysis as 'a systematic, replicable technique for compressing many words of text into fewer content categories based on explicit rules of coding'. This entails working through large amounts of data and extracting meaning from them by grouping and interpreting the information. In this study, content analysis was used not only during the literature review but also in analysing the departmental solicited documents, where large amounts of data and statistics were analysed. Firstly, the data reflected in the 2009 and 2010 ATRs were compared with the planned training reflected in the relevant WSPs of both the dti and CIPRO. The primary researcher then compared her findings based on the document analysis to those made from the individual interviews to support or negate the perceptions of the interviewed participants. This was part of the process of triangulation used by the researchers to verify 
the different findings. Stemler (2001) states that triangulation increases the credibility of a study and its findings because multiple sources of data, methods, investigators or theories are used to verify the data and subsequent research findings.

\section{Strategies employed to ensure quality data}

In addition to the triangulation method described above, the primary researcher ensured quality data were obtained by conducting the interviews in a conference room on the dti premises, albeit separate from the general office buildings. The venue was easily accessible to all participants but also chosen in an effort not to jeopardise the anonymity of the participants at any time. To improve the quality of the analysed primary data during the coding process, the data were coded by the primary researcher as well as a co-coder, who identified areas (themes) of common interest in the interviews.

The quality of the solicited documents were not under the influence of the researchers, but, to ensure the best possible quality, the statistics used were of legally required documents sourced after departmental sign-off and official submission to the PSETA.

\section{Reporting}

The findings are reported in terms of the themes identified supported by verbatim examples of participant responses. A table (see Table 3), summarising the relevant information from the WSPs and ATRs, is provided in order to easily compare it with the finding of the participant interviews. A short discussion of the compared findings of the interviews and document analysis follows, to report whether the statistics supported or negated the participant experiences.

\section{Findings}

Career advancement, accessibility, equality, training and development opportunities and the training nominations were identified as general themes, which, along with the document analysis findings, are discussed in this section. The themes address the aim of the study and were common in the responses of participants. The accessibility theme was identified additionally, as it was a general theme that was mentioned by all participants in different questions during the interviews.

\section{Possibilities for career advancement}

Although the majority of the participants were promoted during their career in the Public Service, it was clear from their reactions that it was not always a positive and motivating experience. A participant explained this paradox as follows:

'... he [my manager] was not willing to promote me because he thought I would not manage to work properly [...] He was not really, ehh, happy before but then eventually I got promoted.' (Participant 5, female, physical disability)

\section{Another participant stated:}

'The fear is the moment that they develop you, then there is a question of losing you or that it places you in a position that they can maybe not even afford; it's not due to monetary restraints; it's the keeping me down, the pulling down syndrome.' (Participant 4, male, physical disability)

Furthermore, one of the participants indicated that he experienced problems with his automatic rank promotion, which was general practice in the Public Service before 2001:

'Rank promotion [...] so after four years you automatically qualify. Which I did not, apparently to them at that stage. They did reimburse me about five or six years back pay at a later stage.' (Participant 1, male, physical disability)

\section{Accessibility}

When considering accessibility to training courses, there were a few positive responses from the participants, for example:

'So far, so good. I didn't experience any problem; whatever [...] I ask for I get [...] assistance.' (Participant 5, female, physical disability)

'I can see that there [are] people that need more help. Fortunately, from my side, I don't think there's too much things that I need for them to support me, but some do.' (Participant 2, male, sensory disability)

However, this experience was not shared by all. One participant, for example, expressed the following misgivings:

'Yes, they provide training to dti employees. The only problem for me I can say is that even though on their forms they say identify if you need something for your disability but when you go there and attend the training they don't make sure they accommodate [you].' (Participant 7, female, sensory disability)

And another participant responded with the following:

'I don't know if people with disabilities will ever be respected as part of the society and especially in CIPRO. Even in training the idea of making special arrangements to accommodate PWD just seems too much and they [would] rather not nominate you than take the responsibility to accommodate you.' (Participant 4, male, physical disability)

Concerns were raised regarding the general accessibility of the dti and CIPRO offices where in-service training and some formal training takes place. A participant shared the following experience:

'Ek sukkel om deure oop en toe te kry, want ons het vreeslike deure wat vreeslik moeilik oop en toe maak, dis swaar deure [...] Veral as jy iets vashou, en jy moet dan nog iets doen en jy moet 'n kaart "swipe" en die deur oopmaak, ek kan nie dit doen nie. [I have difficulty opening and closing doors due to the heavy doors that open and close with difficulty, they are heavy doors [...] Especially if you are carrying something and have to do something else and also scan your card and open the door, I can't do this.]' (Participant 6, female, physical disability)

\section{Equality}

There were some positive responses regarding equality in the dti. One participant stated:

'The dti is doing by all means [everything in its power] to accommodate everyone and not because they want to reach their number, but because of my qualification and the input and the experience that I can provide for the department as compared to other departments.' (Participant 7, female, sensory disability) 
Another participant's response regarding equality was:

'Ek dink hulle gee gelyke kanse vir almal. [I think they provide equal opportunities for all.]' (Participant 6, female, physical disability)

However, there were also negative responses. A participant referred to inequality between different Public Service departments:

'Why do you not give that person this support? But I feel like someone who's not in that situation [and] does not know what the issues are, I feel like, I feel like it needs to change.' (Participant 2, male, sensory disability)

Whilst other participants observed:

'I've seen many PWD because we differ with disabilities, so I must say they were undermined most of the time, and they were not recognised and they will say this is not for them, this is for us.' (Participant 3, male, physical disability)

'[Once] we had a person in a wheelchair that the building was inaccessible to him; we had sort of a fight and a semi arrangement but ahh, not a real solution.' (Participant 1, male, physical disability)

Concerns relating to employment were also raised:

'Another thing is like you find that even the employment of the disabled people is [...] is still very low.' (Participant 2, male, sensory disability)

'... the enforcement of the Employment Equity Act as by the Department of Labour, I see it as a, some kind of a, let me say askew. It's just letting people know that it does exist but the actual implementation of it, this is including the act, is not happening, therefore in whatever level or whatever way, if there could be anyway where this people can be conscientised that these persons with disability are real people and these people need real attention including skills, eh, including their development, then I think that will be best.' (Participant 4, male, physical disability)

\section{Training and development opportunities}

With reference to the training and development opportunities provided, a participant stated:

'... they are trying, they are really trying, it's just that I don't think that they know exactly, they are still not organised to prioritise persons with disability, but they are still trying.' (Participant 5, female, physical disability)

Other participants made the following positive remarks:

'I attended a number of good training [sessions ...] since I joined CIPRO, I got training. I got the skills I need.' (Participant 2, male, sensory disability)

'Ja ek word gestuur op training so ek het nie wat training aanbetref 'n probleem nie. [Yes, I get sent on training and therefore I do not have a problem as far as training is concerned.]' (Participant 6, female, physical disability, [authors' own translation])

A participant commented on improvement in terms of training:

'For the past 10 years or so there was no support given to persons with disability. Only now recently [have] they started giving support [...] for the past two years there is support for persons with disability.' (Participant 3, male, physical disability)

Other participants expressed concern that, when training is requested, it is perceived as irrelevant to the employee's position and that managers become oversensitive if he or she persists with the request:

'... but like I say, what they normally say is that they are not relevant to your position. And then they become tender.' (Participant 4, male, physical disability)

'Indeed there was courses [sic] interested, and that is why I say it is window dressing. I've been fighting with management for the past year, 2 years to put me on a EMDP course and they eventually did and I'm now busy with it $[\ldots]$ as a result of my persistence and not due to their perception that I am going to be a good leader in the next 5 to 10 years.' (Participant 1, male, physical disability)

There were the following frustrations expressed by some participants:

'... while I am here at CIPRO, my job is only specialising on one component of it which, maybe you focus on $2 \%$ of what you're supposed to do and the $90 \%$ on whatever. In the end it's a little frustrating if you do so much for something and in the end you cannot perform it.' (Participant 2, male, sensory disability)

'Not specifically, most of the things I've learned were basically general knowledge to me.' (Participant 1, male, physical disability)

As well as:

'Nowadays you know that a person needs to be computer literate to fit into, eh, to fit into the developments of technological advancement but if you keep on doing [an] entry course, entry course all the way it does not serve a purpose.' (Participant 4 , male, physical disability)

\section{Nominations}

Two participants felt that they only attended training by pressurising management. Participant 7 stated that training followed 'out of my own request' and Participant 1 indicated attendance was 'a result of my persistence'. Another identified the needs as part of the Public Service performance management and development system (PMDS), in line with their performance gaps and career aspirations:

'... in terms of our personal development we need to identify the courses that we need, [...] So most of the courses I do I choose myself, but then it's up to my manager to approve it or not.' (Participant 7, female, sensory disability)

\section{Training and development reports}

As stated, the researchers conducted a literature review and also made deductions from statistical training data collected. This analysis stated the number of PWD that took part in training and development interventions in the dti and CIPRO and served to verify the deductions made from the data collected during the semi-structured interviews with the participants. Comparing the ATRs with the relevant WSPs also revealed to what extent the proposed training for PWD had been achieved. Table 3 presents a summary of the statistics reflected in the 2009 and 2010 WSPs and ATRs for both the dti and CIPRO.

From the data in Table 3, it is clear that, in 2009, both the dti and CIPRO trained more PWD than they had planned. In 2010, CIPRO trained the same number of PWD as planned, 
TABLE 3: Training statistics for the Department of Trade and Industry and the Companies and Intellectual Property Registration Office (2009-2010).

\begin{tabular}{|c|c|c|c|c|c|c|c|}
\hline \multirow[t]{2}{*}{ Year } & \multirow[t]{2}{*}{ Employee classification } & \multicolumn{3}{|c|}{ The dti } & \multicolumn{3}{|c|}{ CIPRO } \\
\hline & & $\begin{array}{c}\text { Full staff } \\
\text { complement }\end{array}$ & $\begin{array}{c}\text { Planned training } \\
\text { - WSP* }\end{array}$ & $\begin{array}{l}\text { Actual training } \\
\text { - } \text { ATR* }^{*}\end{array}$ & $\begin{array}{c}\text { Full staff } \\
\text { complement }\end{array}$ & $\begin{array}{l}\text { Planned training } \\
\text { - WSP* }\end{array}$ & $\begin{array}{c}\text { Actual training } \\
\text { - ATR* }\end{array}$ \\
\hline \multirow[t]{3}{*}{2009} & PWoD & 1079 & 2718 & 1105 & 447 & 273 & 246 \\
\hline & PWD & 9 & 1 & 6 & 8 & 2 & 5 \\
\hline & Training sessions for full staff complement (\%) & 0.80 & 0.09 & 0.56 & 1.79 & 0.45 & 1.12 \\
\hline \multirow[t]{4}{*}{2010} & PWoD & 1166 & 1135 & 1627 & 502 & 502 & 475 \\
\hline & Training sessions for full staff complement (\%) & $\mathrm{n} / \mathrm{a}$ & 97.34 & 139.50 & $\mathrm{n} / \mathrm{a}$ & 100.00 & 94.60 \\
\hline & PWD & 21 & 21 & 0 & 11 & 2 & 2 \\
\hline & Training sessions for full staff complement (\%) & 1.80 & 1.85 & 0.00 & 2.19 & 0.40 & 0.40 \\
\hline
\end{tabular}

Source: Data culled from The dti $(2009,2010)$ and CIPRO $(2009,2010)$. For more information on these sources, please see the full reference list of this article: Van Niekerk, Z., \& Van der Merwe, J. (2013). Participation opportunities for persons with disabilities in training interventions in the dti and CIPRO. SA Journal of Human Resource Management/SA Tydskrif vir Menslikehulpbronbestuur, 11(1), Art. \#466, 12 pages. http://dx.doi.org/10.4102/sajhrm.v11i1.466

11(1), Art. \#466, 12 pages. http://dx.doi.org/10.4102/sajhrm.v11i1.466 The dti, The Department of Trade and
disability; PWD, persons with disability.

${ }^{*}$ Multiple training sessions are provided per employee, hence figures larger than $100 \%$ in some cases.

whilst the dti trained none of the 21 PWD planned for and employed by them in 2010. The reports analysed did not reflect what training was given or why a certain group was not trained.

This contradicts the comments from participants that the dti train PWD, whilst those in CIPRO felt they received fewer opportunities:

'Yes they provide training to dti employees. The only problem for me I can say is that even though on their forms they say identify if you need something for your disability but when you go there and attend the training they don't make sure they accommodate.' (Participant 7, female, sensory disability)

'The fear is the moment that they develop you then there is a question of losing you or that it places you in a position that they can maybe not even afford, it's not due to monetary restraints, it's the keeping me down, the pulling down syndrome.' (Participant 4, male, physical disability)

The analysed data from the WSP and ATR therefore do not tally with the comments made by the participants regarding the issue of not being exposed to equal training opportunities. More of the dti participants indicated that, in their experience, the dti exposed them to training equal to that of their ablebodied collegues. However, this was not always reflected in the ATR. In the 2009 ATR (dti, 2009) it was indicated that six PWD received training. Although this figure was higher than the planned one employee with a disability, it was still a very small percentage compared to the staff complement of 1079 employees. The 2010 ATR (dti, 2010) showed that no PWD employed by the dti had received any training compared to the 21 PWD they planned to train in this period according to their WSP.

For CIPRO, the 2009 ATR (CIPRO, 2009) reflected that five PWD were trained, compared to the two that were planned for 2009. In 2010, the ATR (CIPRO, 2010) reflected that two of the PWD were trained in line with the two planned for that year; however, this still only represented $0.40 \%$ of the full staff complement (502 employees). The number of PWD grew from eight in 2009 to 11 in 2010, but only two of them received training in 2009.

\section{Ethical considerations}

The primary researcher applied for ethical approval to conduct the study from the North-West University and also obtained approval from the director general of the dti to conduct the research there. Furthermore, she wrote an introductory letter explaining the aims, methods and reporting of the study to all relevant employees and subsequently obtained informed consent forms from them indicating their willingness to participate. The primary researcher attempted, at all times, to respect the participants, allowing them to expand on their answers as they saw fit and adhering to their right to make their own choices in whether they would participate in the project by giving them an opportunity to withdraw at any time (National Commission for the Protection of Human Subjects of Biomedical and Behavioral Research, 1978). Neither the primary researcher nor any of the participants received any financial benefits for this study.

\section{Trustworthiness Reliability}

During the data analysis, the primary researcher had to substantiate the coding of certain words or concepts and therefore clear rules had to be developed, ensuring that she, and other researchers afterwards, code exactly as intended. The primary researcher had to guard against subjectivity when setting these rules and it was important to ensure that specific themes were identified; otherwise it could damage the credibility of the research study. To counter this, the primary researcher involved a co-coder to ensure that the same themes were seen as the most common. During the coding process, specific words (manifest coding) were counted, such as 'discrimination', 'equality', 'sensitisation', et cetera, and the implied meanings of what participants say (latent coding) were also considered. The latter was important because, although the participants were fluent in English, it was not be their first language, which influenced how they expressed themselves.

\section{Validity}

In this research study, validity was ensured by interviewing the candidates individually in the same environment. Although all interviews were conducted on the dti campus, they were not conducted in the normal day-to-day office space of the participants. Rather, an interview room on the campus, accessible to all participants and conducive to the interviews (quiet, comfortable, non-threatening environment), was used. 
The interviews were also conducted anonymously in order to encourage open and truthful responses. The validity of the data analysis process was ensured by verifying the responses of the interviews with information gathered during the literature and document review and by using a co-coder during the coding process.

\section{Discussion}

In essence, the importance of this study was to determine whether PWD are indeed treated equally when looking at training and development opportunities. In an effort to attain this, three objectives were identified, as described in the 'Research objectives of this study' subsection of the 'Introduction'. The following discussion points were drawn from those objectives and the above findings.

\section{Career advancement}

These responses show that, according to the participants, they experienced problems during their attempts to get promoted. These problems were the result of the perceptions or attitudes of others towards their ability or potential to advance to the next level.

This confirms Lagadien's (1993) findings that the attitudes of others are the main barrier to PWD and from the participant responses it is still evident today. If society has an open mind towards PWD and refrained from stereotyping them, many of the other barriers they face would not exist, because the decision-makers would consider their needs when drawing up policies and legislation. This was again confirmed by Kleynhans and Kotze (2010), who indicate that negative attitudes often keep PWD from promotion opportunities, which was clear in the interview with Participant 5.

\section{Accessibility}

In research by Thomas (2006), it was found that disability is the EE aspect for which there has been the least progress in South Africa - little has been accomplished to make structures and buildings more accessible or to understand the needs of PWD better. This is confirmed by the remarks of the research participants who experience physical challenges in the buildings, as well as the accessibility of training material to Participant 7.

\section{Equality}

Two participants indicated that they think the organisations are trying to ensure equality and Engelbrecht (2010) supports this, stressing that a lot of companies do accommodate PWD as equally as possible, whilst benefiting from these employees' skills and abilities. However, it is the view of the participants - as evidenced by the five negative responses in this regard - that either the training, employment, or the physical workplace of PWD are still not 'equal'. Cassim (2005) states that ensuring equality and democracy in the workplace is dependent on providing equal training and development, career advancement, retaining PWD and ensuring a generally healthy work environment for all employees.

\section{Opportunities for training and development}

The majority of the participants indicated that they were exposed to training and development opportunities; however, five negative responses indicated that the training offered was either not applicable to their work, functioned merely as 'window-dressing' or was seen as repetitive, low-level training. Ngwena (2004) reiterates this by observing that the stereotyping of PWD by employers who consider them incompetent, as well as their low levels of education and skills development, hinder their entrance into, and growth within, the labour market. Therefore, developing people only through low-level, repetitive training, for example, will serve no purpose in preparing them for better careers.

\section{The need for nominations}

Participants felt they were only given the opportunity to attend career-orientated training through their own persistence, or if the need was identified as part of the PMDS process. Engelbrecht (2010) stressed that organisations will only become employers of choice for PWD if they provide training that contributes to the career advancement of PWD. Whilst Kleynhans and Kotze (2010) confer that managers are hesitant to nominate PWD for training because it is seen as coming at a higher financial cost.

\section{Training and development report evaluation}

From the interview data collected, as well as the statistics used during the document review, it is clear that, although the dti and CIPRO are taking steps to employ more PWD and, especially the dti, are taking focused steps to accommodate the needs of their PWD, both departments can improve their attempts to equally develop their PWD. Their present treatment not only limits their career advancement opportunities but, as is clear from their employment levels, their disadvantaged position is not being improved, by virtue of the discrimination they suffered in the past.

Thus, it was found that, compared with the employees without disabilities, the PWD in the two organisations are not equally exposed to ETD interventions, especially those interventions that can lead to career advancement. The skills development targets as envisaged by the JobACCESS strategic framework (DPSA, 2008a) and the White paper on affirmative action (RSA, 1998c) were therefore not met.

\section{Practical implications}

In the interest of ensuring equal participation opportunities for PWD in the training interventions offered by the dti and CIPRO, it is recommended that both ensure that all supervisors and managers undergo disability sensitisation and management training. Their policies and especially recruitment and training practices have to be updated in order to prevent discrimination on the grounds of disability. Furthermore, the policies and employment equity plans should include active measures and targets to ensure the employment and development of PWD through training and development interventions. PWD should be nominated 
for training related to their work, as well as for training that can lead to career advancement, for example, supervisory or management training.

It is also recommended that PWD receive fair representation during the compilation of the WSP and the planning for training interventions. A good guideline may be to ensure that at least $2 \%$ of the planned training will involve PWD, in line with the $2 \%$ employment target set by government.

\section{Limitations of the study}

The small sample of participants as a result of the limited numbers of PWD employed in South Africa - only $0.6 \%$ of the formal labour force in 2010 (CEE, 2010a) - and the fact that the study was only conducted in the dti and CIPRO, complicates the generalisation of the findings of this study. Future studies that extend to other government departments or the private sector could provide a better understanding of the extent to which PWD are exposed to training and development opportunities.

\section{Suggestions for future research}

According to the World Bank (2012), in sub-Saharan Africa it was found that for social issues, and especially the alleviation of poverty of PWD, research is very limited, clearly stressing the need for research in this field. Future studies on the equal treatment of PWD will contribute to this research field which needs more exposure. Similar studies in other government departments and the private sector can contribute valuable information on the equal treatment of PWD and identify areas for improvement. Research into the types and levels of courses attended by PWD can also provide information to managers to plan better for appropriate training, which could lead to higher levels of performance and career advancement.

\section{Conclusion}

From the above discussion, it was clear that PWD still experience problems with attending training and getting promoted as a result of the prejudiced mindset of managers towards PWD and their potential to be successful in more senior positions. The participants also experienced discrimination from colleagues and felt that other staff members have to be sensitised on issues of disability to understand it better. Concerns on the implementation and enforcement of the EE Act (RSA, 1998a) in terms of reasonable accommodation and the employment of PWD were also raised.

Whilst some participants indicated that training and development opportunities were offered, they had negative perceptions of these opportunities as they felt that they were low-level courses or that they did not teach them any new skills. These participants felt that those opportunities offered to them contributed little to their career advancement, possible promotion or career growth. Furthermore, they mentioned that during training sessions, facilitators and other participants were not sensitised to PWD and that their special needs were not accommodated.
In 2011, during his State of the Nation address, President Zuma (2011) declared 2011 'a year of job creation through meaningful economic transformation and inclusive growth'. One can only hope that this will also lead to higher levels of employment and growth for PWD in the future and provide an end to the marginalisation of this group of our population in the democratic South Africa, awarding equal human rights and opportunities to all.

\section{Acknowledgements}

The authors wish to thank the dti and CIPRO for allowing the researcher to conduct this project at their offices. The authors acknowledge the valuable comments of two anonymous referees on an earlier draft. All remaining errors remain the sole responsibility of the authors.

\section{Competing interests}

The authors declare that they have no financial or personal relationships which may have inappropriately influenced them in writing this article.

\section{Authors' contributions}

J.V.D.M. (North-West University) supervised Z.V.N. (NorthWest University), who conducted this project as part of her Magister Educationis in Training and Development dissertation. Z.V.N. was responsible for the research design and the collection of the data, whilst J.V.D.M. made further conceptual contributions to the analysis. All authors contributed to writing the dissertation.

\section{References}

Cassim, K. (2005, 18 April). Addressing the disability issue at work. The Star, p. 3. Commission for Employment Equity. (2010a). Annual report: Part 1. Pretoria: Government printer.

Commission for Employment Equity. (2010b). Annual report: Part 2. Pretoria: Government printer.

Commission for Employment Equity. (2012). Annual report. Pretoria: Government printer.

Companies and Intellectual Property Registration Office. (2009). Workplace skills plan and annual training report. Pretoria: CIPRO.

Companies and Intellectual Property Registration Office. (2010). Workplace skills plan and annual training report. Pretoria: CIPRO.

Crous, F. (2004). The social needs and problems of higher education students with impairments. Acta Academica, 36(2), 200-220.

Department of Higher Education and Training. (2010). National skills development strategy III. Pretoria: DHET.

Department of Labour. (2003). Technical assistance guidelines on the employment of $P W D$. Pretoria: DoL.

Department of Public Service and Administration. (2006). JobACCESS 2006-2010: One strategy, different paths. Pretoria: DPSA.

Department of Public Service and Administration. (2007). Handbook on reasonable accommodation for PWD in the Public Service. Pretoria: DPSA.

Department of Public Service and Administration. (2008a). JobACCESS strategic framework on the recruitment, employment and retention of PWD in the Public Service. Pretoria: DPSA.

Department of Public Service and Administration. (2008b). JobACCESS implementation guidelines and plan on recruitment, employment and retention of PWD. Pretoria: DPSA.

Department of Trade and Industry. (2009). Workplace skills plan and annual training report. Pretoria: The dti.

Department of Trade and Industry. (2010). Workplace skills plan and annual training report. Pretoria: The dti.

Engelbrecht, A. (2010). Disabled employees: Reasonable accommodation in the workplace. Enterprise Risk, February, 25. 
Fraser-Moleketi, G.J. (2008). Foreword. In Department of Public Service and Administration, JobACCESS strategic framework on the recruitment, employment and retention of $P W D$ in the Public Service, (pp. 1-2). Pretoria: DPSA.

Hergenrather, K.C., Rhodes, S.D., Turner, A.P., \& Barlouw J. (2008). PWD and employment: Application of the self-efficacy of job-seeking skills scale. Journal of rehabilitation, 74(3), 34-44.

International Labour Organization. (2010). Disability in the workplace: Company practice. Working paper No. 3. Geneva: International Labour Organization Printing Offices.

Kleynhans, R., \& Kotzé, M. (2010). Managers' and employees' attitudes towards people with physical disabilities in the workplace. Tydskrif vir Geesteswetenskappe, 50(3), 404-417Lagadien, F. (1993). The power of potential of people with disabilities. Retrieved March 22, 2011 from http://www.independentliving.org/docs4/lagadien. html

Leedy, P.D., \& Ormrod, J.E. (2005). Practical research: Planning and design. (8th edn.) Upper Saddle River: Pearson. PMCid:1895012

Lengnick-Hall, M.L., Gaunt, P.M., \& Kulkarni, M. (2008). Overlooked and underutilized: PWD are an untapped human resource. Human Resource Management, 47(2) 255-273. http://dx.doi.org/10.1002/hrm.20211

National Commission for the Protection of Human Subjects of Biomedical and Behavioral Research. (1978). Belmont report: Ethical principles and guidelines for the protection of human subjects of research. Washington, D.C.: National Institutes of Health.

Ngwena, C. (2004). Equality for PWD in the workplace: An overview of the emergence of disability as a human rights issue. Journal for Juridical Science, 29(2), 167-197.

Ratcliff, D. (2002). Qualitative data analysis and transforming moment. Transformation, 25(2), 116-133.

Republic of South Africa. (1995). White paper on the transformation of the Public Service. Pretoria: Government printer.

Republic of South Africa. (1996). The Constitution of the Republic of South Africa (Act No. 108 of 1996). Pretoria: Government printer.

Republic of South Africa. (1998a). The Employment Equity Act (Act No. 55 of 1998). Pretoria: Government printer.
Republic of South Africa. (1998b). The Skills Development Act (Act No. 97 of 1998). Pretoria: Government printer.

Republic of South Africa. (1998c). White paper on affirmative action. Pretoria: Government printer.

Republic of South Africa. (2000). The Promotion of Equality and Prevention of Unfair Discrimination Act (Act No. 4 of 2000). Pretoria: Government printer.

Services Sector Education and Training Authority. (2006). Employing and managing PWD. Parktown: Services SETA.

Statistics Canada. (2006). Participation and activity limitation survey 2006: Analytical report. Retrieved June 15, 2010, from http://www.statcan.gc.ca/pub/89-628x/89-628-x2007002-eng.htm

Statistics South Africa. (2003). 2001 National Census report. Pretoria: StatsSA.

Statistics South Africa. (2007). Community survey report. Pretoria: StatsSA.

Statistics South Africa. (2012). 2011 National Census report. Pretoria: StatsSA.

Stemler, S. (2001). An overview of content analysis. Practical assessment, research \& evaluation, 7(17), 137-146.

Thomas, D.R. (2006). A general inductive approach for analysing qualitative evaluation data. American Journal of Evaluation, 27(6), 237-246.

United Nations. (2008). United Nations convention on the rights of PWD. New York: UN.

Vila, M., Pallisera, M., \& Fullana, J. (2007). Work integration of PWD in the regular labour market: What can we do to improve these processes? Journal of Intellectual \& Developmental Disability, 32(1), 10-18. http://dx.doi.org/10.1080/1366825 0701196807, PMid:17365363

World Bank. (2012). Disability in Africa region. Retrieved March, 28, 2012, from http:// web.worldbank.org/wbsite/external/topics/extsocialprotection/extdisability/0, ,contentmdk:20183406 menupk:417328 pagepk:148956 pipk:216618 thesite pk:282699,00.html

World Health Organization. (2011). World report on disability. Geneva: WHO Library Cataloguing in Publication Data.

Zuma, J. (2011). Press release: State of the Nation address. Pretoria: Government printer. 